Andere Bluttlecke als die an den Brustklappen des Rockes fanden sich aber an demselben nicht vor. Demnach gutachtete ich:

1) dass das an dem Rock befindliche Blut älter ist als vom 3 . November 1885 und sehr füglich in Februar 1885 an den Rock gekommen sein kann,

2) dass neues Blut über dem alten an dem Rocke nicht befindlich gewesen ist.

In dem Audienztermin äusserte der Criminal-Commissarius, dass er als alter Criminalist, auf unser Gutachten nichts gäbe. Er hätte frische Blutspritzen neben altem Blute bemerkt. Wenn er auf denselben gekratzt habe, so sei es darunter frisch roth geworden, (!) und sie hätten sich leicht abreiben lassen.

Der Vorsitzende fragte uns: ob frisch angetrocknetes Blut leicht $a b-$ reibbar sei, so dass wir bei unserer Untersuchung dasselbe nicht mehr vorgefunden haben könnten.

Ich konnte darauf nur erwidern, dass im Allgemeinen frisch angetrocknetes Blut eine leicht zerreibliche Masse bilde, welche durch Reiben Ieicht von der Unterlage fortgebracht werden könne, dass aber die Leichtigkeit der Fortschaffung abhänge von dern Stoffe, auf dem das Blut sich befinde, und namentlich leicht die Fortschaffung von Wolle, also von einem Tuchrocke sei. Aber im concreten Falie seien diese angeblich frischen Blutspritzen mit Kreide umzeichnet gewesen, die man noch sähe, und diese Spritzen seien in unsere Untersuchung mit einbezogen gewesen, so dass die Angaben des Criminal-Commissarius auf Irrthümern berubten.

4.

\title{
Ueber einen Aortenriss mit Bildung einer falschen Klappe.
}

\author{
Von Dr. Gustav Fütterer, \\ I. Assistenten am pathologischen Institut zu Würzburg.
}

(Hierzu Taf. IX. Fig. A.)

Das Ergebniss einer Section giebt mir Gelegenheit einen Aortenriss zu beschreiben, welcher in mehrfacher Hinsicht besonderes Interesse verdient.

Aus dem klinischen Theile will ich nur hervorheben, dass die auscultatorischen Erscheinungen, welche von Herm Prof. Leube intra vitam beobachtet wurden, denselben veranlassten, eine Insufficienz der Aortenklappen za diagnosticiren.

Durch die Section wurde diese Diagnose bestätigt, in einer Weise jedoch, wie es nicht erwartet werden konnte.

Der Sectionsbefund war folgender:

An den Extremitäten war starkes Oedem, in der Bauchhöhle reichlich klare braungelbe Flüssigkeit, ebenso in beiden Pleurahöhlen, besonders rechts. 
Das Herz war ețwas nach links verdrängt und vergrössert; dasselbe überragte die linke Mamillarlinie.

Im Pericardialsack war wenig klare gelbe Flüssigkeit vorhanden.

Die Atrioventricularostien waren gut durchgängig, die Klappen der Pulmonalarterie schlossen, dagegen floss in die Aorta eingegossenes Wasser 2war langsam, aber stetig und vollständig ab, auch dann, wenu das Herz - un jede Zerrung der Klappen zu vermeiden - nicht an der Aorta, sondern an den Vorböfen gehalten wurde.

Die Musculatur des linken Ventrikels hatte an ihrer dicksten Stelle, ohne die Trabekeln, einen Durchmesser von $18 \mathrm{~mm}$, eine nicht unbeträchtliche Hypertrophie, besonders wenn man berücksichtigt, dass auch Dilatation vorhanden war.

Der Klappenapparat des Herzens, einschliesslich der Aortenklappen, war völlig intact und die Ursache der Insufficienz fand sich erst oberhalb der letzteren.

Hier war in der Aortenwand ein Querriss vorbanden, welcher über der Mitte der rechten Klappe beginnend, quer über die hintere und linke Klappe hinweg, stetig höber steigend bis zum linken Schnittrande der Aorta verlief, zweimal unterbrochen von kleinen Säulen stehengebliebener Intima und Media, welche zügelartig je von den oberen Berübrungspunkten der hinteren und rechten und der hinteren und linken Aortenklappe schräg nach links und oben - die linke Säule jedoch mehr direct nach oben - verliefen, un dort Füblung mit dem oberen Rande des Risses zu suchen; der linken Säule gelang das nicht vollständig, während die rechte mit dem grössten Theile ihrer Fasern den oberen Rissrand erreichte. Beide Säulen gingen übrigens hier oben in einander äber und bildeten so einen Bogen, welcher die bintere Klappe überspannte. Unterbalb dieses Bogens setzte der Riss sich nun bis hinter die unter ihm Jiegende Aortenklappe fort, no hier in halber Höhe derselben zu enden; derselbe hatte auf dieser ganzen Strecke zur Ablösung einer Platte geführt, welche ans der Intima und einem Theile der Media bestehend, eine taschenartige Einbuchtung binter sich einschloss, deren hintere Wand von einer Schicht elastischer Fasern - dem äusseren Theile der Media - und der Adventitia gebildet wurde. Diese dünne Schicht elastischer Fasern war auf dem Durehschnitt in der ganzen Ansdehnung des Risses als feine weisse Linie zu verfolgen und unter ihr fanden sich auf der Höhe der immerbin sehr geringen Ausbuchtung kleine Blutbeerde in der Adventitia, welche kaum die Grösse eines Stecknadelkopfes überschritten.

Die innere Oberfläche des Gefässes zeigte hier ein grauröthliches, röthlich gesprenkeltes Aussehen. Durch die mikroskopische Untersuchnng wurde die Richtigkeit der makroskopischen Beobachtungen bestätigt.

An Schnitten, welche die hintere Aortenklappe, die hinter dieser gelegene abgelöste Platte und die ganze Gefässwand bis oberbalb des Risses durchtrennten, fand sich Folgendes:

1) Ein völliges Fehlen des Endothels in der ganzen Ausdehnung des Risses and auch in dera oberhalb des letzteren gelegenen Theile der Aorta, 
letzteres gewiss genügend erklärt durch die lange Zeit, welche nach dem Tode des Individuums verflossen war, ehe die Leiche zur Section kam.

2) Entsprechend dem makroskopischen Befunde eine continuirliche Schicht elastischer Fasern, welche hier mit der Adventitia zusammen die Wand des Gefässes bildeten. Diese Schicht wurde rom oberen Rande des Risses bis zu dessen Mitte staffelförmig dünner und bestand an dieser dünnsten Stelle nur noch aus einer äusserst feinen Lage elastischer Fasern, durch deren Interstitien hindurch kleine Blutaustritte stattgefunden hatten. Von hier nach abwärts nabm die Mächtigkeit dieser Schicht in gleicher Weise wie sie dort abgenommen wieder $z u$; bis zu der Stelle wo die oben erwähnte losgelöste Platte der Gefässwand aufsass (der tiefste Punkt des Risses).

Der Widerstandsfähigkeit dieser elastischen Schicht und ihrer äusserst festen Verbindung mit den elastischen Fasernetzen an der Basis der losgelösten Platte ist es wohl zu verdanken, dass nach dieser Richtung keine Vertiefung des Risses stattfinden konnte. Auch oben an der dünnsten Stelle batten die wenigen elastischen Fasern dem Blutdruck genügend lange zu widerstehen vermocht, denn hier konnten

3) auch Heilbestrebungen constatirt werden. Durch die dünnsten Stellen der elastischen Fasern hindurch hatten von der Adventitia herkommende Granulationen ibren Weg gebahnt und zur Bildung kleiner Fleckehen von Bindegewebe auf der inneren Wand des Risses gefübrt.

Diese mikroskopischen Beobachtungen zeigen, dass nicht nur eine vollständige Zerreissung der Aortenwand schon verhütet worden war, sondern dass auch schon Heilungsvorgänge begonnen hatten, welche gewiss zu einer Ausheilung resp. Vernarbung des Risses geführt haben würden, wenn nicht durch andere Ursachen der Tod des Individuums bedingt worden wäre.

Eine besondere Besprechung verdient noch die schon öfter erwähnte, aus Intima und dem inneren Theile der Media bestehende losgelöste Platte, welche ich als "falsche Klappe" bezeichnen möchte und zwar, weil ich annehmen muss, dass sie intra vitam als Klappe functionirt, dass sie die Function der hinteren Aortenklappe bis zu einem gewissen Grade übernommen hat.

Zur Rechtfertigung dieser Annahme kann ich Folgendes anführen:

1) Ueberragte die in das Aortenlumen vorgabuchtete falsche Klappe die hintere Aortenklappe so, dass beim Rückstoss der durch die Systole des Herzens in die Aorta hineingetriebenen Blutsäule wohl eine accidentelle Füllung der letzteren, keineswegs aber eine Ausnutzung ihrer elastischen Eigenschaften, eine Anspannung, ein Klappenschluss zu Stande kommen konnte. Dagegen machte sich der Blutdruck auf die "falsche Klappe" direct geltend, buchtete dieselbe noch weiter vor und brachte eine solche Ueberragung über den freien Rand der hinteren Aortenklappe und eine solche Vorwölbung derselben in die Tasche der Aortenklappe hinein zu. Stande, dass diese sich mit ihrem freien Rande der ersteren dicht anschmiegen musste, so dass auch selbst die angenommene accidentelle Füllung nur in sehr geringem Grade stattgefunden haben kann. 
2) Aber war anch wirklich eine Aorteninsufficienz vorhanden, was gewiss zur Genüge erwiesen ist durch die intra vitam beobachteten auscultatorischen Erscheinungen, ferner durch die vorhandene starke Hypertrophie des linken Ventrikels, für welche keine andere Ursache aufzufinden war und zuletzt durch das Resultat der Schlussprobe, welche, wie oben erwähnt, mit aller Vorsicht vorgenommen wurde.

Da nun jedoch die Aortentlappen völlig intact waren, so kann die Aorteninsufficienz ja nur durch ein Functioniren der "falschen Klappe“ resp. die dadurch bedingte Ausserfunctionssetzung der binteren Aortenklappe bedingt worden sein.

Resumiren wir nun kurz das Gesagte, so haben wir es mit einer unvollständigen Zerreissung der Aortenwand dicht über den Klappen zu thun, bei welcher nur kleine Blutaustritte stattgefunden haben und bei welcher durch die Widerstandsfähigkeit der erhaltenen elastischen Schicht Heilungsvorgänge begünstigt wurden. Ferner aber kam es zur Ablösung eines Theiles der Aortenwand, welcher vom Blutdruck in das Lumen des Gefässes vorgebuchtet wurde, die eine Aortenklappe überragte und diese selbst ausser Function setzte. Da nun aber die Function dieser "falschen Klappe“ immerhin nur eine unvollständige sein konnte, so wurde dadurch eine Aorteninsufficienz mit ihren Folgen bedingt.

Zur Erklärung der beigegebenen Zeichnung muss ich noch bemerken, dass mit dem zur mikroskopischen Untersuchung herausgeschnittenen Stücke zugleich das Stück stehengebliebener Intima und Media, welches oben als "linke Säule" bezeichnet wurde, fortgenommen und in Folge dessen nicht mitgezeichnot worden ist.

a Hintere Aortenklappe (durchschnitten).

b Falscbe Klappe (durchschnitten).

c Rechte, d linke Aortenklappe. 